\title{
O LeITE dA PEDRA: A IdealizaÇÃo da AmÉrica, a Partir da CÂmera de Três Cineastas Italianos: Giuseppe Tornatore, Irmãos Taviani, Emanuele Crialese
}

Maria CÉlia Martirani Bernardi Fantin

RESUMO: O presente estudo visa propor uma reflexão sobre o conceito de América idealizada, especialmente, a partir do início do século XX, em que as levas migratórias italianas, iludidas com a visão paradisíaca da Nova Terra, partiam com a esperança de reconstruir uma vida digna, em que a fome, o abandono e a miséria da terra natal fossem esquecidos. Nesse intuito, buscaremos analisar as dimensões que a partida da Itália em direção à América parece assumir, em particular, sob a ótica de três cineastas italianos contemporâneos: Giuseppe Tornatore, Irmãos Taviani, Emanuele Crialese.

PALAVRAS-CHAVE: imigração italiana; América idealizada; identidade; cultura; cinema italiano. 
ABSTRACT: La presente ricerca vuole riflettere sul concetto di America idealizzata, sopratutto, all'inizio del secolo XX, quando gli immigranti italiani, illusi con la visione paradisiaca della Nuova Terra, partivano con la speranza di ricostruire una vita degna, in cui la fame, l'abbandono e la miseria della terra natale fossero dimenticati. Con questo scopo, cercheremo di analizzare le diverse dimensioni di questo viaggio dall'Italia in America, in particolare secondo l'ottica di tre registi italiani contemporanei: Giuseppe Tornatore, Fratelli Taviani, Emanuele Crialese.

PAROLE CHIAVE: immigrazione italiana; America idealizzata; identità; cultura; cinema italiano.

ABSTRACT: This research proposes a reflection about the conception of the idealized America, mainly, since the beginning of the $20^{\text {th }}$ century, when lots of italians had to immigrate to the United States of America, completely illuded by a paradise's vision of the New Land, as a land of salvation. In this way, we'll try to analyse, respectively, tree of the most important contemporary movie's directors, not just in Italy, but in the whole world: Giuseppe Tornatore, Brothers Taviani, Emanuele Crialese.

KEYWORDS: italian immigration; idealized America; identity; culture; italian movie. 


\section{Introdução}

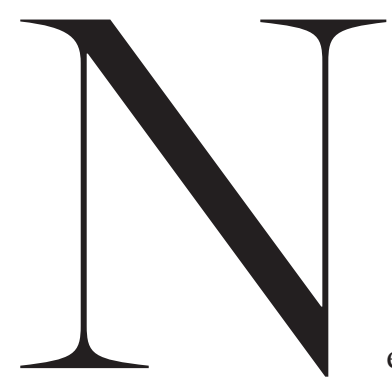

este estudo, gostaríamos de propor uma reflexão em torno da complexa questão dos movimentos migratórios, tão atuais e polêmicos, no contexto da nova geografia humana, que vem se desenhando, de modo peculiar e persistente, sobretudo a partir de primórdios do século XX.

De fato, a nova tendência que, cada vez mais, abre espaço, não só nos meios acadêmicos, como também, na crítica contemporânea abalizada, por meio de resenhas, ensaios, artigos e diversas produções bibliográficas de toda ordem, parece sinalizar uma tentativa de compreensão dos fenômenos de movimentos das massas migratórias, inseridos no atual contexto social, político e econômico e, como não poderia deixar de ser, literário e artístico. Daí por que, de modo bastante reiterativo, proliferem estudos, no âmbito que se passou a denominar, genericamente, como o campo dos "hibridismos culturais" e "estudos culturais". ${ }^{1}$

Tendo em vista a atualidade e importância do tema, nossa proposta se centralizará no modo pelo qual três cineastas italianos contemporâneos - Tornatore, Taviani e Crialese - enfrentaram, especificamente em seus respectivos filmes: La leggenda del pianista sull'oceano (1998), Good Morning Babilonia (1987) e Nuovomondo (2006), a mais que conhecida saga dos imigrantes italianos que buscavam, na América, a salvação para suas vidas, o oásis para suas sedes, o mito paradisíaco, para onde correm os famintos de corpo e de espírito... 


\section{La legenda del pianista sull'oceano de Tornatore: a América na retina do olhar}

O filme de Tornatore (1998) é fruto da adaptação feita para o cinema do monólogo Novecento do escritor italiano contemporâneo Alessandro Baricco (2002). O cineasta captou, muito bem, a euforia, a sensação de total arrebatamento, transfigurada no olhar daqueles que, ainda dentro do grande transatlântico Virgínia (que transportava milhares de italianos, naquele início do séc.XX, para a América), eram os primeiros a ter o privilégio da epifânica primeira visão da ilha de Manhattam, que anunciava o fim daquela difícil e corajosa travessia oceânica.

O que a América representou, a princípio, em particular, para o pobre imigrante que, dentro dos navios abarrotados de gente, singrava mares, em busca de melhores condições de vida, pode ser sintetizado, talvez, na palavra “esperança”. Não faltam, no conjunto das obras literárias italianas e, também universais, as que abordam, de modo profundo e comovido, como o imigrante vivenciou (com o tanto de contradições e sofrimentos que isso pudesse causar) o chamado "sonho americano". Apenas a título ilustrativo, selecionamos importante trecho, extraído da obra Cristo si èfermato a Eboli, de Carlo Levi (1990, p. 108, grifo nosso):

Per la gente di Lucania, Roma non è nulla; è la capitale dei signori, il centro di uno Stato straniero e malefico. Napoli potrebbe essere la loro capitale, e lo è davvero, la capitale della miseria, nei visi pallidi, negli occhi febbrili dei suoi abitatori, nei "bassi" dalla porta aperta pel caldo, l'estate, con le donne discinte che dormono a un tavolo, nei gradoni di Toledo; ma a Napoli non ci sta più, da gran tempo nessun re; $\mathrm{e}$ ci si passa soltanto per imbarcarsi. Il Regno è finito: il regno di queste genti senza speranza non è di questa terra. L'altro mondo è l'America. Anche l'America ha, per i contadini, una doppia natura. È una terra dove si va a lavorare, dove si suda e si fatica, dove il poco denaro è risparmiato con mille stenti e privazioni, dove qualche volta si muore, e nessuno più ci ricorda; ma nello stesso tempo, e senza contradizione, è il paradiso, la terra promessa del Regno.

Voltando ao filme de Tornatore, ele transfigura, plasticamente, a chamada primeira "aparição" da América, conseguindo como que ilustrar, por meio da "imagem em movimento" (JAMESON, 1995) que é, em síntese, uma das definições da linguagem cinematográfica, a primeira página da obra de Alessandro Baricco. 
De fato, a página que "abre" o monólogo, refere-se à tal aparição como algo de encantado, maravilhoso, um fascínio associado, ao mesmo tempo, à dúvida e ao medo do novo (aquele que primeiro a via, ficava como que extasiado e anunciava, com os pulmões cheios de ar, como marinheiro que, antes de todos, avistasse terra: América!) Interessante notar que essa primeira visão da América, coincidindo com a abertura da obra e também do filme, parece querer enfatizar o quanto havia de expectativas geradas, em torno do simples nome América. Veja-se o seguinte:

\begin{abstract}
Succedeva sempre che a un certo punto uno alzava la testa... e la vedeva. È una cosa difficile da capire. Voglio dire... Ci stavamo in più di mille, su quella nave, tra ricconi in viaggio, e emigranti, e gente strana, e noi... Eppure c'era sempre uno, uno solo, che per primo... la vedeva. Magari era li che stava mangiando, o passeggiando, semplicemente, sul ponte... magari era li che si stava aggiustando i pantaloni... alzava la testa un attimo, buttava un occhio verso il mare... e la vedeva. Allora s’inchiodava, lì dov'era gli partiva il cuore a mille, e, sempre, tutte le maledette volte, giuro, sempre si girava verso di noi, verso la nave, verso tutti, e gridava (piano e lentamente): l'America. Poi rimaneva li, immobile come se avesse dovuto entrare in una fotografia, con la faccia di uno che l'aveva fatta lui, l'America. (BARICCO, 2002: 11, grifo nosso)
\end{abstract}

Essa primeira impressão, tão fascinante e idealizada, vai marcando os passageiros do Virginia, que, depois de a terem visto, deverão necessariamente desembarcar e pisar em terra firme, encarando todos os desafios do novo mundo.

Numa leitura mais crítica, poderíamos, talvez, reconhecer na atitude inesperada de Novecento - o menino que nasce dentro do navio e que vive toda uma existência da "proa a popa”, tornando-se um grande pianista e optando por lá morrer - de não querer, jamais, sair do navio, uma espécie de resistência aos falsos e ilusórios chamados de uma América "salvadora", "mítica", "regeneradora", em que todos os sonhos humanos seriam passíveis de concretização. ${ }^{2}$ De fato, no final do filme, em consonância com o final do livro, ao tentar explicar ao amigo (transtornado com a sua decisão) os motivos que determinaram a sua escolha, ele não poupa argumentos, a fim de questionar as falsas aparências e os traiçoeiros chamados do tal mundo, além do convés. Ao dizer que o assusta tudo aquilo que é sem limite, que é grande demais, bom demais, espetacular demais, em certa medida, Novecento estaria, também, a dizer: - Cuidado com essa idéia distorcida de paraíso terrestre: América!

No fundo, Novecento questiona a tal esperança cor de rosa, estampada no olhar dos que viam a América pela primeira vez e se inebriavam diante daquela visão magistral. Ele questiona, criticamente, a que tipo de liberdade essa falsa ilusão poderia levar.

\footnotetext{
2. O monólogo Novecento, de Alessandro Baricco (2002) apresenta um narrador que contará a história de um menino que nasce dentro do navio Virgínia, que levava imigrantes italianos à América, exatamente, na virada do século XIX para o século XX (daí, também a alusão ao título do livro). Este menino, que será batizado, por seu pai adotivo, como Danny Boodmann T. D. Lemon Novecento, passará toda a existência dentro do navio, se tornará um grande pianista e jamais optará por sair de lá. A atitude de Novecento de não descer daquele espaço móvel flutuante deixa indignado o amigo - narrador da história, que é um músico trompetista. Para mais informações a respeito ver FANTIN, M. C. A arte de narrar em Alessandro Baricco: à procura do velho narrador que habita em cada um de nós. 2008. 145 f. Dissertação (Mestrado em Literatura Italiana) - Faculdade de Filosofia Letras e Ciências Humanas da USP, São Paulo, 2008.
} 
Ao salvar a criancinha deixada num caixote - em que as inscrições T.D. Lemon representariam, metonimicamente, a Itália meridional, reconhecida como produtora de limões e, agora, tão empobrecida a ponto de não conseguir sustentar seus próprios filhos, abandonando-os à própria sorte - o negro americano Danny Boodmann confere sentido à sua própria existência. $\mathrm{O}$ menino levará adiante seu nome e, inclusive, ascenderá socialmente, depois de sua morte, infringindo as normas pré-estabelecidas, a de que, por exemplo, os operários não deveriam subir aos espaços nobres do navio. O pequeno Novecento sairá do espaço subalterno das galés - em que só ficavam os carvoeiros e operadores que, efetivamente, faziam com que a máquina navegasse - e passará a transitar pelos espaços da primeira classe, sendo reconhecido e valorizado por meio daquilo que o torna um indivíduo: a música, a sua arte.

Interessa notar que, a essa justaposição do nome, a essa fusão América - Itália (e tudo o mais a que isso possa remeter), o termo "Novecento" acrescenta toda a euforia, o glamour, a ebulição de um novo tempo que, paradoxalmente, antecipará algumas das fases mais patéticas e angustiantes da história da humanidade, como, por exemplo, as duas grandes guerras e a as sangrentas lutas operárias. Nosso protagonista, assim, já no nome preanunciará essa profunda e densa contradição: a de representar, simbolicamente, a porta de entrada para o século XX.

Porém, por mais que esse século possa remeter à idéia de grandes contingentes humanos em movimento, à imagem das massas migratórias, das massas operárias, enfim à massificação do ser humano, cada vez mais diluído e despersonalizado, o narrador (muito bem representado no filme de Tornatore) nos alerta que Novecento não nascerá para ser mais um número, um a mais na multidão. É o que responderá seu pai americano, quando lhe perguntarem sobre o nome que escolhera para o filho adotivo:

- É un'idea buona, Sam, L’ho trovato nel primo anno di questo nuovo, fottutissimo secolo, no? Io lo chiamerò Novecento.

- Novecento?

- Novecento.

- Ma è un numero!

- Era un numero: adesso è un nome. (BARICCO, 2002: 21)

Em todo esse longo aprendizado, em seu aparentemente estreito universo movediço, o que protege e salva o menino-homem pianista de todas as dúvidas e aflições é a música, a arte. 
Aliás, é diante da primeira grande dor (da perda do pai) que o menino vai aprendendo - ouvindo os sons que fazem fundo à cerimônia daquele adeus, enquanto jogam o corpo de seu pai morto no mar - a sublimar as dilacerações de seu espírito, ainda criança. Percebe que "aquilo" o conforta, transcende-o, liberta-o. Esta primeira impressão é tão significativa, que tem a força de impulsioná-lo, tal como a força impetuosa das águas daquele oceano, quase como que de arrancá-lo do mundo dos porões, do carvão, conduzindo-o ao salão mais nobre do navio, numa total superação do medo do novo, do proibido. Às escondidas, num surto de felicidade clandestina, descobre o piano e, completamente atraído pelo instrumento, como se desde sempre o conhecesse, começa a tocar...

É comovente e, ao mesmo tempo, irônica a descrição que, no livro, encontramos sobre o aparecimento de Novecento diante dos demais "habitantes" daquele navio. Neste momento preciso, o menino nasce para o mundo, além das galés, e subverte, por meio de sua música, os regulamentos, as normas vigentes até então:

Suonava non so che diavolo di musica, ma piccola e... bella. Non c'era trucco, era proprio lui a suonare, le sue mani, su quei tasti, Dio sa come. E bisognava sentire cosa gli veniva fuori...

- Come si chiama?

- Novecento.

- Non la canzone, il bambino.

- Novecento.

- Come la canzone?

Era quel genere di conversazione che un comandante non può sostenere più di quattro o cinque battute. Sopratutto quando ha appena scoperto che un bambino che credeva morto non solo era vivo ma, nel frattempo, aveva anche imparato a suonare il pianoforte.... Avrebbe voluto dire molte cose, in quel momento, e tra le altre "Dove cazzo hai imparato?" o anche "Dove diavolo ti eri nascosto?". Però, come tanti uomini abituati a vivere in divisa, aveva finito per pensare, anche, in divisa. Così quel che disse fu: "Novecento, tutto questo è assolutamente contrario al regolamento."

Novecento smise di suonare. Era un ragazzino di poche parole e di grande capacità di apprendimento. Guardò con dolcezza il comandante e disse: "In culo il regolamento!" (BARICCO, 2002, p. 24-25). 


\section{Good Morning Babilonia dos Fratelli Taviani: vencendo uma América Intolerante}

Aclamado pela crítica e público, Good Morning Babilonia é uma produção dos consagrados Fratelli Taviani, Paolo e Vittorio, autores das obras-primas Padre Padrone (1977), Kaos (1984), La notte di S. Lorenzo (1982), entre tantas outras.

Trata da história de dois irmãos toscanos, Nicola e Andrea que precisam imigrar para os Estados Unidos, em busca de uma vida melhor. Artistas artesãos, herdam do pai o dom e o talento de pintar afrescos e azulejos das catedrais italianas. Acabam indo parar em Hollywood. Só depois de muito sofrimento e sabotagens feitas, intencionalmente, por um arrogante e preconceituoso americano, a quem, na ocasião, eram subalternos, conseguem, finalmente, vencer. Passam, então, a trabalhar na construção dos cenários suntuosos do filme Intollerance (1916), épico do famoso cineasta americano D.W.Griffith, conhecido como o criador da linguagem cinematográfica.

Além da interessante proposta de linguagem metacinematográfica, pois o filme é, essencialmente, uma ode de amor à sétima arte e a um de seus grandes diretores (no caso, Griffith), o que nos chama a atenção, também, é o modo como os Taviani tratam da questão da chegada de Nicola e Andrea em terras americanas.

Mais uma vez, ainda de dentro do navio que os conduz à nova vida, a primeira aparição da América vem do olhar, a partir de uma minúscula escotilha... A maestria dos diretores apresenta esta cena carregada de nuances de densa poeticidade.

De fato, após a longa e desafiadora viagem, a imagem que se lhes aparece é a da cidade de N.York, associada a uma lembrança que os dois trazem da infância: a aparição, diante dos olhos extasiados dos dois meninos, da grande e luminosa árvore de Natal (preparada em sua casa, em sua cidade de origem, na Itália, no fim de ano). O que se estabelece, assim, é a analogia, por meio de imagens, do significado da primeira visão da América. Esta, com tudo que carrega de grandioso e surpreendente, seria comparada à mesma visão que os dois meninos tinham como maravilhosa, diante da exuberante árvore de Natal da infância. Nos dois casos, a mesma surpresa, o mesmo êxtase, a mesma sensação de respiração suspensa dos que primeiro viam a América em Novecento, de Baricco (2002) e em La leggenda del pianista sull'oceano, de Tornatore (1998).

Mas parece-nos importante analisar, também, o diálogo metacinematográfico que se evidencia ao redor de uma das obras-primas do cinema clássico, o filme Intollerance de D.W.Griffith (1916).

Em resumo, este filme apresenta quatro episódios paralelos: a queda da Babilônia (daí o título intertextual dado pelos Taviani a seu próprio filme), a peregrinação de Jesus, o 
massacre dos Huguenotes e um homem e uma mulher em meio à luta do capital e do trabalho, envolvendo sempre um berço que balança e enlaça todas as histórias. Estes quatro eixos temáticos se desenvolvem em uma montagem em paralelo. A imagem deste berço foi colhido por Griffith em um dos famosos poemas do grande Walt Whitman, "Leaves of Grass” (1856), e poderia ser sintetizado, nestes dois versos: “...balança o berço sem cessar/ unificador do aqui e do porvir."

No filme, o berço representa o fio que alinhava os episódios, em que uma mulher balança o berço da humanidade, símbolo da esperança e vida eterna.

Além destes detalhes, cumpre observar que:

O filme Good Morning, Babylon, dos irmãos Paolo e Vittorio Taviani (1987) é uma homenagem ao filme de Griffith e mostra a influência dos filmes italianos, principalmente Cabíria sobre ele. O travelling realizado em uma das cenas da Babilônia é baseado em Cabíria..

Em Intollerance, Griffith faz uso de todas as técnicas desenvolvidas ao longo de sua carreira como diretor. Usa a câmera móvel para seguir as cenas de multidão e faz uma panorâmica do set babilônico, a partir de um balão, usando como inspiração o Cabíria travelling ou movimento Cabíria, muito copiado pelos cineastas americanos na época, devido ao sucesso que o filme italiano obteve. (BUENO, 2007, p. 11-12)

Do que se expôs, fica evidente a homenagem feita pelos cineastas italianos Taviani a Griffith e à América, mas também, em nosso entendimento, na tessitura subliminar do que se pode apreender de Good Morning Babilonia é que, mesmo "americanizados", mesmo tendo-se tornado imigrantes aceitos e integrados à força produtiva do capital holliwoodyano, em nenhum momento, Andrea e Nicola permitiram que a tradição e o respeito ao aprendizado ancestral, vindo, especialmente, a partir da figura paterna e, enfim, do "paese" toscano de origem, se diluíssem ou fossem aniquilados pela onipotência da cultura dominante, da grandiosa nação americana, com toda sua imponência e glamour.

Melhor dizendo, sua “italianidade” se mantém e se preserva, ao longo de toda história, dando conta, de modo complexo e instigante de um dos aspectos cruciais da questão migratória. Apesar da necessidade de busca do "sonho americano", mesmo sendo urgente uma difícil e, tantas vezes, forjada e dolorosa adaptação (veja-se, a exemplo, o momento em que um dos irmãos insiste para que o outro fale com ele em Inglês e não em Italiano. revelando toda a séria dificuldade no aprendizado do idioma "salvador", do idioma ao qual era necessário se submeter para não morrer de fome), mesmo assim, nesta fusão cinematográfica Itália-América, ainda parece subsistir uma resistência digna e altiva de 
assimilação, respeitando as idiossincrasias de cada cultura, a fim de que o indivíduo e sua memória e, enfim, sua raiz, sua cultura e identidade não sejam totalmente anestesiados por discursos e ações de intolerância de toda ordem, como as que lemos e ouvimos, assustados, todos os dias, nos jornais que retratam estes nossos tempos, em que renascem, de modo absurdo, movimentos xenófobos, cuja fonte primeira é a do preconceito e a da não aceitação da alteridade, com tudo que ela comporta.

\section{O leite da pedra: os mares de leite da América paradisíaca}

A primeira cena que abre o filme Nuovomondo (2006) de Emanuele Crialese é impactante. Dois homens, pai e filho, sobem uma montanha altíssima de pedra. Hábeis e ágeis pisam a aridez daqueles rochedos apenas com a planta dos pés que sangram, habituados, desde sempre, à dureza descalça daquele chão. E é, também, pedra o que carregam nas bocas totalmente cerradas. Estão sós e sua solidão é ampliada em meio a um mundo que parece feito de calcário branco acinzentado, a se perder de vista nesta espécie de agreste siciliano. Os dois vão escalando o cume escarpado. A única música que se ouve é a dos ruídos dos corpos em movimento, quase como a batida compassada de seus corações aflitos e dos pios de aves agourentas.

A primeira pergunta que, inevitavelmente, fazemos é: para onde estarão indo essas criaturas tão abandonadas, que palmilham aquelas pedras com tamanha desenvoltura, carregando, no olhar, apenas, urgências? E o que se descobrirá, após esse árduo trajeto, é que estão indo ao alto, em direção a um Santuário. Lá depositam as pedras que retiram da boca, em oferecimento ao Senhor, em penitência, para que Ele os oriente, dando-lhes um sinal qualquer que indique a melhor escolha: ficar ou partir. E o veredicto acabará sendo o mesmo que impulsionou tantas levas de pobres italianos meridionais a aventurarem-se nos navios, que os levariam à América, ao Novo Mundo, na esperança de uma vida digna.

Esse primeiro momento se fecha com uma tomada de cena em que a câmera, lentamente, se afasta dos dois e vai flagrando-os do alto, como se os sobrevoasse. Nessa panorâmica, o efeito que se cria é de uma plasticidade singular. Os dois homens vão se tornando diminutos, até a diluição total em meio àquele relevo silencioso e absoluto das pedras que se impõem, numa reverência ancestral. E, a partir daí, terá início a travessia de Salvatore Mancuso, seus dois filhos e a mãe, além de duas moças, que ele se incumbe de fazer chegarem sãs e salvas à América. 
Aparentemente estamos diante de mais um filme sobre a saga de imigrantes, obrigados a tentar uma nova vida em outra terra, tema já tão bem tratado por outros grandes cineastas, como por exemplo, os irmãos Taviani em Kaos (1984) ou Good Morning Babilonia (1987), Tornatore em La leggenda del pianista sull'oceano (1998) e Gianni Amelio, em L’America. (1994).

Entretanto, o que parece excepcional é a nova linguagem com que Crialese traduz esse tão conhecido e atualíssimo tema. Começa rompendo o previsível, introduzindo, já de saída, no momento do embarque, uma figura feminina de cabelos vermelhos, muito elegante, uma inglesa, que não se sabe ao certo o que estaria fazendo ali, em meio àqueles italianos tão simples, rudes, desprovidos de qualquer refinamento. Ela destoa dos demais, como um estranho no ninho. Aos poucos, damo-nos conta de que se trata de uma mulher errante, uma prostituta, que precisava do respaldo de um marido, para poder entrar na América. Percebendo a disponibilidade de Mancuso, vai se aproximando dele para alcançar seu objetivo.

Interessantíssimo o jogo lingüístico que surge a partir da tradução do nome dela, Lucy em Inglês, que acaba se tornando Luce, em Italiano. E ela parece encarnar essa espécie de luminosidade, não apenas devido aos jogos muito bem feitos de luz que, todo tempo, insistem nas tonalidades acobreadas dos cabelos contrastantes com a alvura da pele, mas principalmente por aquilo que lhe é único, numa complexidade feminina de mistério e sedução. Luce representa o diferente, o que, desde o início, também seduz (talvez como o próprio sonho americano) com promessas de renovação e beleza. E como tudo que é novo, ao mesmo tempo que atrai, amedronta...

Nesse sentido, não é à toa a rejeição por parte da velha mãe de Salvatore, Fortunata, em relação à Luce. Simbolicamente teríamos já, em latência, por trás das máscaras do preconceito, a rigidez de um velho mundo arcaico e fossilizado em rituais de preservação, que se fecha a qualquer possibilidade de mudança. E, de fato, tal impossibilidade atingirá o ápice, no final, quando Fortunata decide voltar sozinha à terra natal. Naquele novo mundo não há lugar para ela, que é signo fidedigno da raiz e da força de uma Sicília longínqua, carregada de rituais e crenças de uma cultura capaz de se bastar a si mesma, talvez rígida como o teor das pedras que a constituem.

Outro grande momento do filme é o que abre a cena da partida propriamente dita. E então teremos apenas o apito doloroso do navio que, lentamente, vai afastando-se do porto. Uma nesga de mar se interpõe entre a multidão de homens que fica e a outra que parte, como se a integridade de um corpo fosse cindida ao meio. A tênue linha de água que os separa vai ampliando-se, aos poucos, dando conta do paulatino, mas decisivo afastamento dos que vão para nunca mais voltar. Quase como morrer um pouco, nessa despedida. Quase como deixar pra trás toda uma vida, uma história, em que só resta o apego 
obstinado à idéia da reinvenção do ser no novo mundo que se anuncia. E o navio passa a ser uma espécie de ventre gigante que abriga a todos, irmãos transitórios da mesma embarcação.

A travessia, então, assume o papel de protagonista e aqueles homens, antes dispersos, passam a se reconhecer. Em tudo que, de alguma forma, já foi reiterado por diversos cineastas ao retratarem essa viagem pelo oceano, a câmera de Crialese assume, aqui, mais uma vez, a força de uma beleza inigualável. Especialmente na cena da tempestade em alto mar, em que os corpos desgovernados são jogados de um lado para o outro, acompanhando a fúria das ondas que oscilam impetuosas, ele consegue ilustrar aquela dor, com a mesma precisão dramática de certos claros-escuros que vemos, por exemplo, nas telas de um Caravaggio.

Finalmente, depois do duro percurso, a chegada: o Golden Gate, a porta de entrada para a América. Os imigrantes que chegam a Ellys Island são submetidos a uma série de exames e testes para que possam ser admitidos no novo mundo.

Um viés de profunda e irônica crítica à mentalidade americana, nesse momento, denuncia a arrogância e a postura extremamente preconceituosa dos "civilizados", em relação aos pobres ignorantes "bárbaros" que acabam de chegar. Toca-se aqui, de modo explícito, na ferida, ainda aberta e muito atual, subjacente às teorias xenófobas de eugenia e de superioridade de raças, sustentadas pelos regimes nazi-fascistas. E teremos o absurdo dessas mentalidades, revelada na justificativa dada pelos agentes americanos, ao submeterem os imigrantes recém-chegados a certos "testes de lógica”. Afirmam eles que a inteligência seria determinada geneticamente e que aqueles povos poderiam representar uma séria ameaça, se não fossem submetidos a uma triagem, já que se sabia que a falta de certas capacidades mentais revelariam uma grave doença contagiosa.

Importa notar a coragem com que, abertamente, o filme denuncia a ferrugem corrosiva do preconceito e da política de higienização, camuflada no Portão Dourado de entrada para as facilidades da nova terra. O preço para nadar nos amenos rios de leite da Califórnia (imagem recorrente, à época, para falar da fartura das terras americanas) é muito mais alto do que, de longe, se poderia supor... E parece ser justamente nisso, nesse eixo de tensão que se estabelece entre a ânsia e a necessidade de sair da terra de origem e a integração esforçada, na difícil assimilação dos novos padrões da terra de chegada, que reside uma das muitas qualidades da obra de Crialese.

Sabiamente, muito além da história da saga de italianos obrigados a buscar trabalho e vida digna no eldorado paradisíaco, o filme traz à tona a problemática atualíssima das questões migratórias de nossos tempos, em que o mapa geográfico do mundo implica novas configurações humanas. 
A última cena, quase surreal, aproximará, num close, a câmera de Mancuso, Lucy e dos dois filhos, de quem só veremos as cabeças, já que os corpos estão submersos no grande mar de leite em que nadam. Uma cenoura gigante corta-lhes a frente e, satisfeitos, eles se apóiam nela, usando-a como bóia.

Gradualmente, tal como no momento inicial do filme, a câmera vai distanciando-se em movimento de ascensão, como se os sobrevoasse, e o que se nos apresenta é um imenso fundo branco, o oceano de leite em que milhares de cabeças, com seus chapéus negros, nadam.

A abertura e o final do filme são construídos, formalmente, de modo coincidente. No início, os Mancuso, peregrinos pastores sicilianos, vão diluindo-se no gigantesco universo montanhoso das pedras que parece absorvê-los por completo. Ao final, também, como que se diluem na imensidão branca do mar de leite da América. Talvez, a diferença resida em que, no primeiro momento, sejam ainda seres autênticos que integram aquele ambiente, meio homens-meio pedras, num entranhamento íntimo de convívio com a terra, que só se conhece, por meio da raiz umbilical e única da identidade e do reconhecimento.

Nadando no mar de leite, ao contrário, ainda que com todas as facilidades sedutoras e fascinantes da nova vida, os Mancuso deixam a pedra ancestral e correm o risco de não saber mais quem, de fato, são, em meio à multidão anônima dos que perambulam por aí errantes, talvez, na eterna busca de uma simples, mas verdadeira, identidade.

\section{Conclusão}

Hoje, mais do que nunca, se alargam as questões em torno do que se passou a denominar "multiculturalismo", tendo em vista a reconfiguração geográfica, tanto espacial, quanto política e humana destes nossos tempos.

Nomes como alguns, apenas citados, de passagem, no corpo deste nosso estudo, passam a fazer parte de qualquer pesquisa que tangencie tal problemática: Giddens, Stuart Hall, Canclini, Barbero, Castells, Bauman, entre tantos outros. Os desdobramentos que vêm surgindo a partir da análise destes autores, com suas respectivas visões sobre o problema, crescem e se multiplicam, cada vez mais, na área das ciências humanísticas, sob variados campos, como, por exemplo, o do já citado de "hibridismos culturais".

Justamente porque percebemos a urgência de abordar tais questões é que nos propusemos a analisar três linguagens cinematográficas distintas, criadas por três grandes nomes da cinematografia, não só italiana, mas internacional, tal como se deduz das páginas que, aqui, desenvolvemos. 
Mais do que analisar a adaptação fílmica, por exemplo, feita por Tornatore, a partir da obra de Baricco; mais do que evidenciar que o filme dos Irmãos Taviani pode ser entendido como apologia à arte cinematográfica; mais do que constatar que o filme de Crialese traz uma nova abordagem de um dos temas mais explorados pelo cinema e pela literatura, qual seja o da viagem transoceânica dos pobres imigrantes italianos, que eram obrigados a deixar a terra natal "per cercar di fare l'America", nosso intuito foi o de ir além, buscando refletir, especialmente, como cada um destes cineastas tratou do mito da América idealizada, enquanto Paraíso de salvação. 


\section{Referências bibliográficas}

BARICCO, A. Novecento: un monologo. Milano: Feltrinelli, 2002.

CANCLINI, N. G. Consumidores e cidadãos. 4. ed. Rio de Janeiro: Ed. da UFRJ, 1999.

CASTELLS, M. O poder da identidade. São Paulo: Paz e Terra, 1999.

CRIALESE, E. Nuovomondo. Direção: Emanuele Crialese. Gênero: Aventura. Elenco: Charlotte Gainsbourg, Vincenzo Amato, Aurora Quattrocchi, Francesco Casisa, Filippo Pucillo, Federica De Cola, Isabella Ragonese, Vincent Schiavelli, Massimo Laguardia, Filippo Luna, Andrea Prodan, Ernesto Mahieux, Robert Allyn, Adriana Angrisano, Antonio Angrisano, Cetti Arancio, Tom Bocanelli, Antonio Bruschetta, Oriana Celentano, Doriana Chierici, Nino D’Agata, etc. Duração: 124 min. País de origem: Itália/ Alemanha/ França. Idiomas: Italiano. Legendas: Português/ Inglês. Distribuidora: Imagem Filmes. Site oficial: http://www. goldendoor- movie.com. 2006.

FANTIN, M. C. A arte de narrar em Alessandro Baricco: à procura do velho narrador que habita em cada um de nós. 2008. 145 f. Dissertação (Mestrado em Literatura Italiana) - Faculdade de Filosofia Letras e Ciências Humanas da USP, São Paulo, 2008.

GIDDENS, A. The consequences of modernity. Cambridge: Polity (publisher), 1999.

HALL, S. Identidades culturais na pós-modernidade. Rio de Janeiro: DP\&A Editora, 1997.

JAMESON, F. As marcas do visível. Rio de Janeiro: Graal, 1 ed, 1995.

LEVI, C. Cristo si è fermato a Eboli. Torino: Einaudi, 1990. p.108.

TAVIANI, P\&V. Good Morning Babilonia. Direção: Irmãos Taviani. Gênero: Drama. Elenco: Vincent Spano, Joaquim de Almeida, Greta Scacchi, Désirée Nosbusch, Omero Antonutti, Bérangère Bonvoisin. Duração: 120 min. País de origem: França, Estados Unidos, Itália. Região: 4. Idiomas: Italiano. Legendas: Português. Sistema de som: Dolby Digital 2.0. Formato de tela: Wildescreen. Distribuidora: Versatil. 1987.

TORNATORE, G. La leggenda del pianista sull'oceano. Baseado na obra Novecento de Alessandro Baricco. Direção: Giuseppe Tornatore. Gênero: Drama. Elenco: Bill Nunn, Tim Roth, Pruitt Taylor Vince, Nicola Di Pinto, Gabriele Lavia, Anita Zagaria, Luis Molteni, Adriano Wajskol, Melanie Thierry, Peter Vaughan, Duração: 165 min. Produção: Itália. 1998. 